\title{
Tricuspid Valve Regurgitation
}

National Cancer Institute

\section{Source}

National Cancer Institute. Tricuspid Valve Regurgitation. NCI Thesaurus. Code C50843.

The backflow of blood from the right ventricle into the right atrium, owning to imperfect functioning/insufficiency of the tricuspid valve. 